\title{
BRAND INNOVATIVENESS EFFECTS ON PERCEIVED QUALITY, SATISFACTION AND LOYALTY
}

Ravi Pappu, University of Queensland, Australia

Pascale Quester, University of Adelaide, Australia

\begin{abstract}
Research on the interface of innovation and branding is limited. For example, managers receive little guidance regarding how consumers' perceptions of a brand's innovativeness affect firm performance metrics such as consumer brand loyalty. Moreover, research examining linkages between innovativeness and customer satisfaction is considered critical. Hence, this study provides a conceptual framework for these relationships using associative network theory and brand signaling theory. Structural equation modeling is employed to test the conceptual framework using data collected from a consumer sample (N =355). Results contribute to branding and innovation theories by uncovering the indirect effect of brand innovativeness on customer satisfaction via perceived quality. The study advances innovation research by uncovering the mediating role of perceived quality in the relationship between brand innovativeness and brand loyalty. Unlike the majority of studies which examine innovativeness from a managerial perspective, we conceptualize innovativeness from the consumer's perspective, and at brand level. The results can help new product managers better understand complex routes through which consumer perceptions of innovativeness affect perceived quality and customer satisfaction and thereby brand loyalty.
\end{abstract}

References Available Upon Request 